\title{
Avaliação política da política de estado de turismo de Minas Gerais
}

\author{
Polity assesment of the tourism public policy in Minas Gerais State
}

Evaluación política de la política de turismo del Estado de Minas Gerais

Mariana Pereira Chaves Pimentel ${ }^{1}$

Thiago Duarte Pimentel ${ }^{2}$

Este artigo foi recebido em 01 de AGOSTO de 2018 e aprovado em 22 de MARÇO de 2019

Resumo: Objetiva-se com o trabalho avaliar o processo de elaboração da política de estado de turismo de Minas Gerais. Parte-se do pressuposto de que a Secretaria de Turismo do Estado de Minas Gerais e a política de turismo implantadas a partir de 1999 introduzem profundas alterações na gestão estadual do turismo. Teoricamente, faz-se uma revisão da reforma do Estado, das políticas públicas e das políticas em turismo no Brasil. Metodologicamente, utilizam-se como métodos a pesquisa bibliográfica, o estudo de caso e a entrevista semiestruturada. Quanto aos resultados, tem-se como ator determinante para a criação da Secretaria e da política o próprio Executivo. O contexto teórico e administrativo para a formulação da política foi a reforma gerencialista do Estado. Considera-se que outras influências, como o modelo francês de regionalização do turismo e o Programa de Desenvolvimento do Turismo no Nordeste, também foram determinantes para o modelo de governança resultante.

Palavras-chave: ciclo de políticas públicas, avaliação política, turismo

Abstract: This paper aims to evaluate the process of elaboration tourism public policy of Minas Gerais state. It is assumed that the Tourism Secretariat of the State of Minas Gerais and the tourism policy implemented since 1999 introduce profound changes in the state tourism management. Theoretically, a review of state reform, public policies and tourism policies in Brazil is carried out. Methodologically, bibliographic research, the case study and the semi-structured interview are used as methods. As for the results, the executive itself has as a determining factor for the creation of the Secretariat and of politics. The theoretical and administrative context for the formulation of the policy was the managerial reform of the State. It is considered that other influences such as the French model of regionalization of tourism and the Program of Tourism Development in the Northeast were also decisive for the resulting governance model.

Key words: policy cycle, political evaluation, tourism

Resumen: El objetivo del trabajo fue evaluar el proceso de elaboración de la política de turismo del Estado de Minas Gerais. Se parte del supuesto de que la Secretaría de Turismo del Estado de Minas Gerais y la política de turismo implantadas a partir de 1999 introducen profundos cambios en la gestión estatal del turismo. Teóricamente, se hace una revisión de la reforma del Estado, de las

\footnotetext{
${ }^{1}$ Doutora em Ciências Sociais pela Universidade Federal de Juiz de Fora — UFJF, Juiz de Fora/MG, Brasil. E-mail: marianachaves82@yahoo.com.br.

${ }^{2}$ Doutor em Ciências Sociais pela Universidade Federal de Juiz de Fora — UFJF, Juiz de Fora /MG, Brasil. E-mail: thiago.pimentel@ich.ufjf.br.
} 
AVALIAÇÃO POLÍTICA DA POLÍTICA DE

ESTADO DE TURISMO DE MINAS GERAIS
Mariana Pereira Chaves Pimentel Thiago Duarte Pimentel

políticas públicas y de las políticas en turismo en Brasil. Metodológicamente, se utilizan como métodos la investigación bibliográfica, el estudio de caso y la entrevista semiestructurada. En cuanto a los resultados, se tiene como actor determinante para la creación de la Secretaría y de la política el propio ejecutivo. El contexto teórico y administrativo para la formulación de la política fue la reforma gerencialista del Estado. Se considera que otras influencias como el modelo francés de regionalización del turismo y el Programa de Desarrollo del Turismo en el Nordeste también fueron determinantes para el modelo de gobernanza resultante.

Palabras-Claves: ciclo de políticas públicas, evaluación política, turismo

\section{Introdução}

Apesar de receber pouca atenção dos analistas, o turismo vem chamando a atenção dos governos principalmente por sua relevância como categoria econômica e fator de desenvolvimento econômico-social. Em Minas Gerais, o turismo é inserido na Constituição estadual em 1989, já em 1999, com a criação da Secretaria de Turismo de Minas Gerais — SETUR, deu-se início à construção de uma política pública de turismo.

Contudo ainda são escassas as investigações e análises sobre os processos que deram origem à política de turismo no estado ou mesmo no País. Apesar do boom das três últimas décadas, o campo de análise de políticas públicas ainda é bastante incipiente no Brasil pós-redemocratização (MELO, 1999; RUA, 2007, FARAH, 2013; FARAH, 2016), e os estudos sobre as políticas de turismo são ainda mais esparsos.

De modo geral, as investigações sobre as decisões políticas debruçam-se sobre a origem dos problemas que tais decisões procuram resolver, sobre as soluções formuladas e as condições de sua implementação (ARAÚJO; RODRIGUES, 2017). Mais recentemente, uma profusão de abordagens, teorizações e vertentes analíticas buscam dar significação à diversificação das aplicações derivadas do receituário gerencialista assumido após a crise do Welfare State, bem como aos processos de formação, gestão e análise das políticas públicas, considerando um mundo cada vez mais caracterizado pela interdependência, incerteza e complexidade das questões públicas (FARIA, 2003).

Para Cavalcanti (2007), a análise de políticas públicas contempla a descrição do conteúdo da política; a análise das consequências de forças do sistema político (econômicas e/ou políticas); a investigação sobre o efeito dos arranjos institucionais e processos políticos; e a avaliação das consequências das políticas públicas na sociedade, em termos dos efeitos esperados ou inesperados. Esta última - a avaliação de políticas públicas — normalmente está interessada na "eficácia das políticas, descartando a avaliação política dos princípios que as fundamentam e, em decorrência, o seu próprio conteúdo substantivo [...]” (FIGUEIREDO; FIGUEIREDO, 1986, p. 108). 
AVALIAÇÃO POLÍTICA DA POLÍTICA DE

ESTADO DE TURISMO DE MINAS GERAIS
Mariana Pereira Chaves Pimentel Thiago Duarte Pimentel

Assim, a questão que orientou esta pesquisa foi quais atores, contexto, ideias, valores e critérios estão na gênese de política de estado de turismo de Minas Gerais adotada em fins da década de 1990? Para responder a essa questão, o objetivo do trabalho é realizar a avaliação política da política de estado de turismo de Minas Gerais, entendendo por avaliação política a análise e elucidação do critério ou critérios que fundamentam determinada política; dos inputs (ideias, valores e normas), withinputs (pressões e arranjos institucionais) e input channels (partidos, organizações) do sistema político ${ }^{3}$.

Parte-se da premissa inicial de que a inovação que a Secretaria de Turismo do Estado de Minas Gerais e a política de turismo adotada representam não é desprezível, introduzindo profundas alterações tanto de ordem política, como administrativa, estratégica e operacional, que necessitam seriamente de ser avaliadas. Argumentamos aqui, no entanto, que a PPTur de Minas Gerais, no período em tela (1999-2017) é fruto da atuação do executivo estadual, de forma ad hoc, guiado pelos princípios da NPM, materializadas por meio de uma síntese assistemática em programas e projetos que priorizaram oportunisticamente temas e formas valorados no contexto da época.

Esse trabalho justifica-se pelo fato de que, se as políticas públicas variam em consonância com as características políticas, sociais e econômicas locais (HALL, JENKINS, 2004), resta conhecer quais problemas se colocavam para atores e formuladores, opções políticas disponíveis e modos de enfrentamento selecionados pelo governo mineiro no final da década de 1990. Uma vez que as políticas exigem teorias (BROOKS, 1993), o estudo das políticas de turismo empreendido pode, então, contribuir para a tomada de decisões no estado de Minas Gerais. Ainda, se os estudos sobre as políticas públicas brasileiras são recentes (FREY, 2003), as políticas de turismo carecem de desenvolvimentos tanto empíricos, como teóricos.

Para a construção desse trabalho, estruturou-se em quatro partes, além da introdução. A seguir, apresentam-se algumas discussões teóricas acerca do estado, das reformas administrativas e das políticas em turismo no Brasil. Na sequência, apresenta-se o percurso metodológico utilizado na concepção da pesquisa. Posteriormente, constrói-se a análise sobre o processo de criação da SETURMG e de formulação da política de estado de turismo de Minas Gerais. Finalmente, são tecidas algumas considerações finais.

\section{Estado, reformas administrativas e políticas em turismo no Brasil}

\footnotetext{
${ }^{3}$ Easton (1957) entende o processo político como um sistema, em que atores e instituições são enquadrados por um conjunto de normas, símbolos e valores (inputs), cujos comportamentos são condicionados por pressões e mecanismos internos do sistema (withinputs), que o alimentam e mantêm ativo, por intermédio dos input channels (partidos, grupos de interesses, intelectuais, organizações internacionais).
} 
AVALIAÇÃO POLÍTICA DA POLÍTICA DE

ESTADO DE TURISMO DE MINAS GERAIS
Mariana Pereira Chaves Pimentel Thiago Duarte Pimentel

Entre os anos 1930 e 1960, alguns estados foram promotores de intenso crescimento econômico e de importantes benefícios sociais, os chamados Welfare States ${ }^{4}$. Neste período, principalmente após a Segunda Grande Guerra, assistiu-se a um momento de prosperidade econômica e a um aumento das condições de vida, sem precedentes na história da humanidade (BRESSERPEREIRA, 1998b). Porém esse crescimento econômico-social não se deu de maneira equânime, e o Welfare State foi responsabilizado por redução das taxas de crescimento econômico, elevação do desemprego e aumento da inflação que ocorreram em todo o mundo a partir dos anos 1970. Como resposta, surgiram reformas econômicas, orientadas para o estado, chamadas neoliberais, que esperavam como resultado o estado mínimo.

De fato, a grande tarefa do estado moderno, notadamente nos anos 1990, é a reforma ou reconstrução. Nos anos 1990, a proposta neoliberal apresenta sinais de fracasso, despontando-se como alternativa a reconstrução do estado como garantidor não só da propriedade e dos contratos, mas também dos direitos sociais. Para Bresser-Pereira (1998a), são principalmente quatro os problemas com os quais a reforma do estado se depara: i) econômico, com relação ao tamanho do estado; ii) econômico-político, refere-se à redefinição do papel regulador do estado; iii) econômicoadministrativo, diz respeito à recuperação da capacidade financeira de implementação das decisões tomadas pelo governo; e iv) político, no que tange à governabilidade, ou capacidade de o governo mediar conflitos de interesses, garantir legitimidade e governar.

No Brasil, em 2008, completaram-se duzentos anos de estado nacional, administração pública e reformas institucionais e administrativas. Abrucio (2007), em seu intuito de separar o joio do trigo da trajetória reformista brasileira, considera que os resultados foram desiguais e fragmentados para o conjunto do estado, e que alguns outros não foram devidamente atacados. Para Paula (2005), a nova administração pública continua reproduzindo o autoritarismo e o patrimonialismo, pois o processo decisório continuou como um monopólio do núcleo estratégico do estado e das instâncias executivas. Para Souza (2006), a busca por eficiência e resultados das últimas décadas fez ressurgir a importância do campo de conhecimento denominado políticas públicas, assim como de instituições, regras e modelos que regem decisão, elaboração, implementação e avaliação.

Não existe uma única, nem melhor, definição sobre o que seja política pública. As políticas públicas, segundo Rua (1997), resultam do processamento, pelo sistema político, de inputs ambientais e withinputs (demandas do próprio sistema político), e tanto inputs, como withinputs expressam

\footnotetext{
${ }^{4}$ De acordo com Esping-Andersen (1991), o Welfare State envolve responsabilidade estatal no sentido de garantir o bemestar básico dos cidadãos.
} 
demandas (serviços, participação) ou suportes (regulamentos, tributos). Dye (2009, p. 1), de maneira mais unilateral, sintetiza a definição de política pública como "o que o governo escolhe fazer ou não fazer". Essas definições, centradas prioritariamente na tomada de decisão governamental, cederam gradualmente lugar a outras perspectivas, em que novos atores políticos (ARRETCHE, 1996; MILANI, 2008), arranjos institucionais (FARAH, 2001), redes (MARQUES, 2006; STONE, 2008, HECLO, 2008), e arenas (LOWI, 1964) ganham notoriedade.

A análise de políticas públicas, como campo disciplinar de estudo, surge e desenvolve-se nos Estados Unidos, no pós-guerra, em condições em que a intervenção do estado na resolução de problemas exigia crescente informação. Os cientistas sociais norte-americanos Harold Lasswell, Herbert Simon, Charles Lindblom e David Easton são considerados os fundadores do estudo das políticas públicas, como área científica autônoma, pelos trabalhos desenvolvidos a partir dos anos 1950.

Lasswell foi um dos primeiros autores, em 1956, a tentar estabelecer um conjunto de etapas de desenvolvimento do processo político. Easton (1957), por sua vez, desenvolve a perspectiva sistêmica à análise das políticas públicas. As políticas públicas são, em seu modelo, um output do sistema político, revelador da emergência, da natureza e da atividade do estado. Easton entende o processo político como um sistema, em que atores e instituições são enquadrados por um conjunto de normas, símbolos e valores (inputs), cujos comportamentos são condicionados por pressões e mecanismos internos do sistema (withinputs), que o alimentam e mantêm ativo, por intermédio dos input channels (partidos, grupos de interesses, ideologias, intelectuais, organizações internacionais).

Segundo Howlett e Ramesh (1995), os processos político-administrativos de resolução de problemas têm caráter dinâmico; por isso, o policy cicle subdivide o agir público em fases parciais e sequenciais: a definição da agenda, a formulação da política, a tomada de decisão, a implementação, e a avaliação. Quanto ao primeiro estágio, vale mencionar a obra de John Kingdon (2011), Agendas, alternatives and public policies, em que desenvolve "o modelo analítico Multiple Streams" procurando explicar como é que os problemas se transformam em problemas políticos, isto é, como captam a atenção do público e dos políticos e entram na agenda da ação pública. Nem todas as questões se transformam em problemas políticos suscitando a intervenção do governo.

Segundo Araújo e Rodrigues (2017), no modelo de análise proposto, procura-se responder às seguintes questões: (a) Por que é que os decisores prestam atenção a um determinado assunto em detrimento de outros? (b) Como e por que se alteram as agendas políticas ao longo do tempo? (c) Como os decisores selecionam soluções para os problemas, dentre um vasto conjunto de alternativas? Argumentam Araújo e Rodrigues (2017), que Kingdon concebe um modelo baseado numa metáfora e 
em três conceitos centrais: as comunidades políticas, constituídas por investigadores, deputados, funcionários públicos, analistas, grupos de interesse, cujos membros partilham a preocupação com determinados temas ou problemas e que promovem a construção e a difusão de ideias em diferentes fóruns; os empreendedores políticos, um tipo particular de atores na mediação e negociação dos processos de agendamento; a janela de oportunidade política, que se abre quando convergem três fluxos de variáveis: a percepção pública dos problemas (fluxo dos problemas), o conhecimento de soluções políticas e técnicas adequadas aos valores dominantes (fluxo das políticas) e as condições de governação (fluxo da política).

Segundo Araújo e Rodrigues (2017), Kingdon inclui ainda nesse fluxo três feixes de variáveis decisivas para alterar ou influenciar o processo de agendamento:

- O sentimento nacional (national mood), que caracteriza como "situações em que um grande número de pessoas num país partilha ideias comuns [...] o sentimento nacional sofre mudanças no tempo, de uma forma perceptível, e estas mudanças têm importantes impactos nas agendas e nos resultados políticos" (Kingdon, 2011, p. 146).

- As forças políticas organizadas, onde os atores centrais são os partidos políticos e os grupos de interesse. A percepção que os decisores têm da forma como estes atores se inter-relacionam é de importância crucial para o desenvolvimento das políticas. Se os governos consideram que "a maioria dos grupos de interesse e outras forças organizadas apontam para uma mesma direção, $[. .$.$] este contexto proporciona-lhes um forte ímpeto para se$ orientarem nessa direção" (Kingdon, 2011, p. 150).

- As mudanças governamentais (governmental turnover), nomeadamente mudanças de ciclo político, remodelações e reconfigurações de governos e parlamentos, mudanças nas hierarquias da administração, sendo a mudança de governo o fator mais propício à ocorrência de alterações na agenda política. Ao contrário do que acontece no fluxo das políticas, em que o consenso é produto de processos de persuasão e difusão, no fluxo da política, os consensos são construídos pelos intensos processos negociais e pelo estabelecimento de coligações. (ARAÚJO; RODRIGUES, 2017, p. 22).

Vários autores consideram que a principal fragilidade do modelo reside na pouca atenção que se dá ao contexto institucional do qual decorre a ação política. Na prática, afirma Frey (1999), os atores político-administrativos dificilmente se atêm à sequência de passos do modelo de policy cicle, especialmente os programas políticos mais complexos que se baseiam em processos de reações mútuas e interações permanentes. Tal fato não indica necessariamente que o modelo seja inadequado para a explicação dos processos, mas sublinha o caráter de tipo idealizador.

Apesar do amplo debate acerca das políticas públicas, no Brasil, os estudos sobre políticas públicas vêm sendo mais sistematicamente realizados, principalmente após a redemocratização (SOUZA, 2006; FARIA, 2003, 2005; PAIVA, 2010). Segundo Faria, ensaios teórico-conceituais e 
pesquisas empíricas têm demonstrado a incapacidade dos modelos tradicionais de interpretação dos mecanismos de intermediação de interesses, como o pluralismo, o corporativismo, o marxismo, em suas várias derivações, de dar conta da diversificação e da complexificação dos processos políticos ${ }^{5}$. Por essa razão, além desses modelos, há hoje uma variedade de vertentes analíticas que buscam dar inteligibilidade à formação e gestão das políticas públicas, como as policy networks, as comunidades epistêmicas, as advocacy coalitions, o policy learning, os processos de policy transfer.

As redes de políticas públicas (policy networks) consistem em um conjunto relativamente estável de relações de natureza interdependente e não hierárquicas entre diversos atores, os quais compartilham interesses comuns em relação a uma política e trocam recursos entre si para atingir tais interesses, reconhecendo que a cooperação é o melhor meio de alcançá-los (BÖRZEL, 1998, p. 254). Peter Haas (1992, p. 3) define comunidade epistêmica como "uma rede de professionais com reconhecida experiência e competência em uma área específica e com autoridade no campo de conhecimento desse âmbito de políticas". O modelo de advocacy coalitions (coalizões de defesa de interesses), apresentado por Paul Sabatier e seus colegas, de acordo com Gonnet (2017), concentra-se nas atividades de formulação de políticas e nos papéis desempenhados pelos atores que compartilham crenças comuns, na articulação e promoção de definições específicas de problemas, e meios de resolvê-los. Esse modelo concentra atenção sobre o papel de ideias, aprendizado e comportamento de coalizão na formulação de políticas. Já o policy learning, de acordo com Dunlop e Radaelli (2012), refere-se a três processos de aprendizado diferentes: aprender sobre organizações, aprender sobre programas e aprender sobre políticas, ora individualizados, ora concomitantes. Tais processos podem referir-se a quem aprende, ao que se aprende ou ao efeito esperado do aprendizado.

Finalmente, o policy transfer refere-se a um processo em que o conhecimento sobre políticas, arranjos administrativos, instituições - entre outros elementos - de um determinado contexto (espaço e tempo), são utilizados no desenvolvimento de políticas, arranjos e instituições em outro contexto. Dolowitz e Marsh $(2000,2012)$ identificam seis categorias principais de atores envolvidos na transferência de políticas, embora, em qualquer caso específico de transferência, mais de uma categoria de ator possa estar envolvido: servidores públicos eleitos (Executivo e Legislativo); partidos políticos; burocratas/funcionários públicos; grupos de pressão; empreendedores políticos/especialistas;

\footnotetext{
${ }^{5}$ De modo geral, para o pluralismo, o estado está sobre a influência de grupos de pressão diversos, com graus de poder diferentes, que atuam na concepção de políticas públicas, determinando o seu conteúdo, sem que haja um grupo dominante. Por corporativismo, entendem-se os agrupamentos de profissionais ou associações representativas de interesses (corporações) nos quais fórmulas de colaboração são capazes de neutralizar elementos de conflito, como as diferenças ideológicas no plano político, e gerar maior capacidade de influenciar os governos em benefício do grupo. Já o marxismo vê o estado como meio de legitimação e dominação de uma classe social sobre outra, dando destaque para o poder econômico na ação política (CUNHA, 2008).
} 
AVALIAÇÃO POLÍTICA DA POLÍTICA DE

ESTADO DE TURISMO DE MINAS GERAIS
Mariana Pereira Chaves Pimentel Thiago Duarte Pimentel

e instituições supranacionais. As lições políticas a serem transferidas são consideradas neutras ${ }^{6}$, e, por isso, apoiadores e opositores de várias vertentes políticas usam essas lições seletivamente para conseguir a adoção de ideias, uma vez que informações sobre os efeitos de um programa em outro lugar podem justificar tomadas de posições.

Se o estudo das políticas públicas no Brasil é recente, a política de turismo, apesar de vir ganhando espaço na agenda governamental nos últimos anos, tem também processos e repercussões ainda pouco conhecidos (PIMENTEL; PIMENTEL; VIDAL, 2016; PIMENTEL; PIMENTEL, 2018). O desenvolvimento do turismo na América Latina, desde o início do século XX, foi gradual e intermitente, mas, a partir da década de 1990, alcançou uma grande expansão.

Em virtude do crescimento da atividade turística mundial, o turismo passa a ser considerado, a partir de 1950, um importante setor para a economia, e muitos estados deixam de considerar o turismo uma atividade econômica secundária (BID, 2006). No Brasil, o turismo entra na agenda pública na década de 1920, mas ainda em forma de políticas governamentais isoladas, sem vínculos fortes na estrutura do estado, e, desde o início, apresenta objetivos de desenvolvimento econômico (PIMENTEL, 2016).

A partir da década de 1960, as políticas em turismo consolidam-se na agenda pública, e formalizam-se no arranjo organizacional estatal. A partir desse momento, o turismo fará parte do projeto nacional com um único objetivo: o desenvolvimento econômico nos moldes das economias líderes mundiais, em conformidade com as diretrizes internacionais sobre o tema para os países subdesenvolvidos, como se nota por ocasião da Conferência das Nações Unidas sobre o Turismo e as Viagens Internacionais, celebrada em Roma em 1963, onde se proclamou:

"[...] o turismo pode contribuir e efetivamente faz uma contribuição vital para o crescimento econômico nos países em desenvolvimento" (KUPER; RAMIREZ; TRONCOSO, 2010). O argumento básico é que "o afluxo massivo de turistas e renda poderia aliviar nos países subdesenvolvidos o déficit estrutural da balança de pagamentos". Ainda, "no contexto político ideológico que vive o mundo neste momento, argumenta-se reiteradamente que o turismo é um importante veículo para alcançar a paz e a compreensão internacional" (ONU, 19637).

Segundo Pimentel (2016), a influência do contexto internacional refletiu-se no Sistema Nacional de Turismo, que reproduziu o modelo de desenvolvimento dos países centrais. Da articulação com a Organização dos Estados Americano (OEA) e a Organização Mundial do Turismo (OMT) foram extraídas muitas metodologias que redundaram na formação de recursos humanos,

\footnotetext{
${ }^{6}$ ROBERTSON, I. Political conflict and lesson drawing. p. 55.

7 "Recomendaciones sobre Turismo y Viajes Internacionales", Conferencia de Roma, ONU, 1963.
} 
divulgação e promoção, além do estabelecimento de sistemas de informações estatísticas (PAIVA, 1995).

A partir da década de 1990, o turismo irá não apenas permanecer na agenda, como se tornar prioridade para os governos, e as políticas em turismo passam a pautar-se pela competitividade nacional no mercado turístico globalizado. O País passa a buscar um melhor posicionamento no mercado turístico mundial e, para isso, define com objetivo a viabilidade e competitividade das empresas e destinos turísticos, de modo que sejam capazes de prosperar e entregar benefícios de longo prazo (PIMENTEL, 2016; PIMENTEL e PIMENTEL, 2018).

No nível nacional, análises similares vêm sendo realizadas, porém mais restritas no escopo e na amplitude temporal das políticas analisadas, por exemplo, focando apenas as PPTur nacionais dos anos 1990 (OLIVEIRA, 2008), ou ainda focalizadas em áreas temáticas, tais como políticas de meio ambiente (WANDERLEY-FILHA; AZEVEDO; NÓBREGA; ALBUQUERQUE, 2013; MELO; MONTEIRO, 2014; RAMOS, 2015; MATHEUS; RAIMUNDO, 2017; ALMEIDA; CASTRO, 2017), de inclusão social (PAULA; MOESCH, 2013; SCHENKEL, 2014) de grupos minoritários (DUARTE; BORDA; MOURA; SPEZIA, 2016).

No nível subnacional (regional), várias análises têm sendo realizadas por pesquisadores brasileiros, em geral, concentrando-se em temas como: (1) fatores espaciais das PPTur (FRATUCCI, 2014; FEGER; ETGES, 2014); (2) influência político-partidária na agenda e sua implementação (SILVEIRA; MEDAGLIA; PAIXÃO, 2014); (3) análise dos atores relacionados com a política, por exemplo, via arranjos institucionais (ENDRES, 2104; PIMENTEL, 2014; CARVALHO, 2015), relação entre stakeholders (VELASCO GONZÁLEZ, 2011; CONTE; COLLETO; TRAVERSO; ELESBÃO, 2014; LEITE; LOPES; MOORI, 2015), análise de redes (KNUPP, 2014) e governança (NÓBREGA; FIGUEIREDO, 2014), ou ainda associação entre eles, como governança/redes/teoria institucional (ENDRES; PAKMAN, 2019) ou por meio de perspectivas críticas e de descortinamento das relações de poder (FLORES; JIMÉNEZ, GRACIELA, PORRAS, FRANCISCO, 2016; MATA; EMMENDOERFER; PIMENTEL, 2018; VELASCO GONZÁLEZ, 2016) ou ainda modelos (GOMES; GÂNDARA, 2014), metodologias (SOLÀ; MORALEDA; MAZÓN, 2012; PIMENTEL; CARVALHO, 2013), indicadores (SAGI, 2009) e fatores condicionantes para o planejamento e a gestão do turismo (CARVALHO E PIMENTEL, 2014); (4) elementos de gestão, tais como regionalização (VIRGINIO; FERREIRA, 2013; BORTOLOSSI; MANTOVANELLI JÚNIOR; SAMPAIO; GUZATTI, 2014; EMMENDOERFER; SOARES; ARAÚJO; MENDES; CUNHA, 2016), descentralização (EMMENDOERFER et al., 2007; TRENTIN; FRATUCCI, 2011; OLIVEIRA, 2014) e inovação (EMMENDOERFER, SILVA; LIMA, 2014). 
AVALIAÇÃO POLÍTICA DA POLÍTICA DE

ESTADO DE TURISMO DE MINAS GERAIS
Mariana Pereira Chaves Pimentel Thiago Duarte Pimentel

Se, em nível federal, a primeira iniciativa de descentralização nas políticas públicas de turismo deu-se no período de 1992 a 2002, com a criação e a implantação do Programa Nacional de Municipalização do Turismo, que propiciou a gestão participativa do turismo por meio de Conselhos Municipais de Turismo, no estado de Minas Gerais, desde 1999. Após a criação da Secretaria de Estado de Turismo, incentivou-se a formação dos circuitos turísticos, que ocorreria por livre iniciativa dos municípios. Segundo dados da SETUR (2002), em fevereiro de 2001, iniciam-se as primeiras oficinas participativas de sensibilização de representantes da sociedade civil e do Poder Público dos municípios para o turismo no estado. O objetivo das oficinas, em consonância com a visão estratégica da política assumida pela Secretaria de Estado de Turismo, era motivar as lideranças dos municípios para a organização de grupos responsáveis pela gestão do turismo regional para a promoção do desenvolvimento turístico. As oficinas eram iniciadas por uma palestra do então Secretário de Estado de Turismo, Manoel Costa, que, segundo Emmendoerfer (2008), foi o principal idealizador do processo.

Além da descentralização, a política de circuitos ancorava-se também na regionalização. No estado de Minas Gerais, a política de regionalização do turismo constituiu-se antes da diretriz nacional e foi formulada pela Secretaria de Estado de Turismo (SETUR/MG), em 2001. Em 2003, foi assinado o Decreto Estadual n. 43.321 de 2003, que dispõe sobre o reconhecimento dos circuitos turísticos e considera-os como: “[...] o conjunto de municípios de uma mesma região, com afinidades culturais, sociais e econômicas que se unem para organizar e desenvolver a atividade turística regional de forma sustentável, através da integração contínua dos municípios, consolidando uma atividade regional”.

A decisão de regionalizar e descentralizar a atividade turística em Minas Gerais seria devido à grande extensão territorial do estado e ao número de municípios (KNUPP; NAVES, 2012; FUCHS; OLIVEIRA, 2012). Além disso, com a regionalização, esperava-se aumentar a permanência média do turista em Minas Gerais e melhorar a infraestrutura local, gerando, assim, mais renda e trabalho para as regiões (OLIVEIRA, 2008) e, ainda, possibilitar a articulação dos agentes das regiões turísticas do estado e o desenvolvimento regional por apresentarem mais condições de atender às demandas existentes (EMMENDOERFER; SOUZA; LORETO, 2012).

Internacionalmente, a França foi um dos países pioneiros na descentralização da gestão do turismo, o que, de acordo com Oliveira (2014), ajudou o país a tornar-se o maior receptor mundial de turistas, gerando renda e desenvolvimento econômico para seus habitantes. Oliveira (2014) afirma que a política de circuitos turísticos mineira foi inspirada no modelo francês de regionalização do turismo e defende que esse processo (de transferência política) tem sido recorrente na área do turismo no País, como é o caso do projeto Excelência em turismo - Aprendendo com as melhores experiências 
internacionais, realizado pelo Ministério do Turismo e do Programa Estrada Real, que, segundo o exSecretário de Turismo de Minas Gerais do governo de Itamar Franco (citado em OLIVEIRA; LEITÃO; FILHO, 2007, p. 8a), "[...] nasceu como um programa estruturante, apoiado no modelo internacional de sucesso do caminho místico que liga a França ao Norte da Espanha". A inspiração do Caminho de Santiago também foi usada em São Paulo para a criação da rota de peregrinação denominada Caminhos de Anchieta, reproduzindo as viagens feitas pelo padre José de Anchieta em nove municípios do estado.

\section{Metodologia}

$\mathrm{Na}$ pesquisa, de cunho qualitativo, usou-se o método de estudo de caso, sob a forma de abordagem empírica do objeto política pública de turismo, focalizando o recorte específico do estado de Minas Gerais. Considerando-se a visão de Thomas Dye, de que tudo que o estado faz (ou deixa de fazer) é uma política pública, e, portanto, haveria uma miríade de políticas púbicas de turismo, segundo os diversos atos normativos, formais e institucionais, desempenhados pelo estado na área de turismo, neste estudo, restringiu-se o foco à análise de uma política considerada estruturante. Tal ação foi implementada com a criação institucional da Secretaria de Turismo, em 1999, e permanece até o presente. Portanto o lapso temporal a que se dedica a pesquisa compreende o período.

Por se tratar de um estudo ex post facto, realizado entre 2015 e 2017, a metodologia de pesquisa não estruturada e exploratória que guiou este trabalho caracteriza-se pela utilização de vários tipos de métodos, como análise de documentos, pesquisa bibliográfica, entrevista (MALHOTRA, 2004). Quanto aos objetivos, essa pesquisa pode ser considerada exploratória, por proporcionar maior familiaridade com o problema, com vistas a torná-lo mais explícito. A grande maioria das pesquisas envolve: (a) levantamento bibliográfico; (b) entrevistas com pessoas que tiveram experiências práticas com o problema pesquisado; e (c) análise de exemplos que estimulem a compreensão. Essas pesquisas podem ser classificadas como: pesquisa bibliográfica e estudo de caso (GERHARDT; SILVEIRA, 2009).

Os dados e as entrevistas foram levantados compreendendo esse período. Três foram as técnicas de recolhimento de dados e informações utilizadas: a pesquisa documental, a observação participante e a entrevista. Como método de coleta de dados, tomaram-se a pesquisa bibliográfica, o estudo de caso e a entrevista em profundidade. A pesquisa bibliográfica é feita com base no levantamento de referências teóricas construídas e públicas, e permite ao pesquisador recolher informações sobre o problema a respeito do qual se procuram respostas. 
AVALIAÇÃO POLÍTICA DA POLÍTICA DE

ESTADO DE TURISMO DE MINAS GERAIS
Mariana Pereira Chaves Pimentel Thiago Duarte Pimentel

Inicialmente, foi realizado o levantamento e a seleção da bibliografia concernente à política de estado de turismo de Minas Gerais e pertinente ao objetivo da pesquisa; feito isso, passou-se à leitura e à análise do material, buscando-se identificar os atores e as referências teóricas, contextuais ou outras que influenciaram a criação da SETUR e da política de turismo. O estudo de caso visou a conhecer em profundidade o como e o porquê de uma determinada situação que se supõe ser única em muitos aspectos (GERHARDT; SILVEIRA, 2009), tomando-se como caso de estudo o estado de Minas Gerais.

Em seguida, foi utilizado o método da entrevista em profundidade, utilizando-se roteiro semiestruturado, aplicado ao superintendente de Políticas de Turismo da SETUR-MG, responsável pela pasta no período de 2012 a 2015, e três técnicos e um assessor, membros da SETUR, ouvidos separadamente e em momentos diferentes, durante 2017. Vale lembrar que entrevista semiestruturada é aquela na qual o pesquisador organiza um conjunto de questões sobre o tema que está sendo estudado, mas permite, e às vezes até incentiva, que o entrevistado fale livremente sobre assuntos que vão surgindo como desdobramentos do tema principal (GERHARDT; SILVEIRA, 2009).

Adicionalmente, procedeu-se à observação participante e a reuniões do Conselho Estadual de Turismo, em 2017, à coleta de documentos institucionais e não oficiais (definitivos), e às discussões temáticas assistemáticas com os membros do referido conselho.

\section{Avaliação política da política de turismo de Minas Gerais}

De modo a atender ao objetivo proposto, discutimos a seguir os elementos do ambiente político-administrativo que circunscreveu a criação da política de estado de turismo; buscando capturar i) o critério ou critérios que fundamentam a política; ii) os atores, as ideias e os valores intervenientes sobre a formulação da política de turismo mineira; iii) o arranjo institucional e as pressões econômicas ou políticas do sistema; e iv) os canais por meio dos quais o tema alcançou a agenda governamental. Vale ressaltar que os fatores diagnosticados não esgotam a multiplicidade de elementos componentes do processo de tomada de decisão política, e que, por isso, não representam a totalidade das referências contextuais do período, apenas exprimem o universo capturado pela pesquisa e tentam explicar, por sua parte, o processo decisório que envolveu a formulação da política de turismo mineira.

Nas décadas finais do século XX, o turismo convertia-se em um tema central nas sociedades latino-americanas pelo propalado potencial de crescimento em ingressos, empregos e renda, e convertia-se em uma das novas rotas pelas quais os governos buscavam alcançar desenvolvimento 
AVALIAÇÃO POLÍTICA DA POLÍTICA DE

ESTADO DE TURISMO DE MINAS GERAIS
Mariana Pereira Chaves Pimentel Thiago Duarte Pimentel

econômico (OCDE, 2012). Segundo Capanegra (2010), a Guerra Fria levou os países industrializados a reconsiderar a situação dos países subdesenvolvidos, que poderiam radicalizar suas posições ideológicas e alinharem-se ao bloco socialista. Dessa conjuntura, desdobram-se as iniciativas de ajuda internacional para o desenvolvimento de países em atraso, e as Nações Unidas promovem o desenvolvimento do turismo internacional como benéfico para esses países.

Já nos anos 1980, o Brasil enfrentava um período de crise econômica, instabilidade política, reorientação ao mercado externo e reformas administrativas. Com a nova Constituição Federal promulgada em 1988, a promoção e o incentivo do turismo foram assumidos como "dever da União, estados e municípios, como fator de desenvolvimento social e econômico" (art. 180). A nova Constituição incorpora o receituário internacional e assume o turismo como contribuição necessária ao desenvolvimento econômico do País. Estimulado pela crise e pelas tendências neoliberais, o turismo, principalmente o internacional, entendido como exportação invisivel por contribuir positivamente para a balança de pagamentos, a partir dos anos de 1990, foi tomado como alternativa para o reequilíbrio das contas públicas, prejudicadas por uma década de crises, e irá estabelecer-se na agenda pública brasileira nas décadas seguintes, até a atualidade, tornando-se protagonista em alguns momentos, como no período de preparação e realização dos megaeventos esportivos.

Alinhando-se a essas expectativas, no estado de Minas Gerais, governado desde 1999 por Itamar Franco, que havia sido presidente da república de dezembro de 1992 a janeiro de 1995, instituise, em 1999, uma Secretaria de Turismo, que absorveria a TurMinas - Empresa Mineira de Turismo. A nova Secretaria passou a ter a "finalidade de planejar, coordenar e fomentar as ações do turismo, objetivando a sua expansão, a melhoria da qualidade de vida das comunidades, a geração de emprego e renda e a divulgação do potencial turístico do estado" (SETUR, 2016).

Segundo Kingdon (2011), as mudanças governamentais podem ser decisivas para influenciar o processo de agendamento de determinado assunto. Nesse caso, a criação da Secretaria de Turismo deu liberdade ao processo de formulação da política de turismo, já que, com a renovação administrativa, representada pela Secretaria de Turismo, associada à inexistência de política anterior, tem-se que a política de turismo estava liberta de problemas de coordenação de políticas, isto é, conflitos de poder, burocráticos, procedimentais, financeiros ou de conteúdo, e livre de tendências, como a continuidade e o incrementalismo ${ }^{8}$. Se, segundo a abordagem incrementalista, são incomuns as mudanças bruscas e rápidas na oferta de políticas públicas, fazendo com que o fornecimento de políticas apresente variações estreitas em relação às ações governamentais precedentes, no caso mineiro, ao contrário, os

\footnotetext{
${ }^{8}$ LINDBLOM, Charles E. The science of "muddling through". Administration Review, vol. 29. p. 79-88, Spring, 1959.
} 
decisores usufruíram do estabelecimento de um arranjo hierárquico e burocrático novo, sem padrões de rubricas ou gastos e sem uma regularidade estabelecida que devesse ser acompanhada.

Vale mencionar que a criação de uma Secretaria de Estado de Turismo não foi fato isolado na década de 1990. Assiste-se, no período, à institucionalização ${ }^{9}$ do turismo nas esferas administrativas de diversos estados brasileiros, refletindo ideias, valores e aspirações do período, como a Secretaria de Turismo do Rio Grande do Norte, criada em 1996; no Paraná, foi criada a Secretaria de Estado da Indústria, do Comércio e do Turismo (hoje denominada Secretaria de Estado do Esporte e do Turismo), em 2001; na Bahia, a Secretaria da Cultura e Turismo foi criada em 1995 (desde 2006 renomeada Secretaria de Turismo).

Assim, durante a década de 1990, segundo o ex-Superintendente de Políticas de Turismo da SETUR:

[...] as pessoas passaram a enxergar o turismo como um vetor de desenvolvimento, ficou latente que o Brasil aproveitava muito pouco seu potencial e então começou a ter uma profusão de secretarias criadas, de cursos de turismo nas universidades [...] Então teve esse movimento, eu me recordo de haver um movimento bem positivo, o turismo vai ser a bola da vez.

Na Secretaria recém-criada, iria definir-se, também, uma Política de Estado de Turismo, "em articulação com órgãos e entidades das esferas de governo federal, estadual ou municipal”, visando à gestão das regiões turísticas do estado por meio de circuitos turísticos (SETUR, 2016). A despeito de ser incentivada pela SETUR, a formação dos circuitos turísticos deveria ocorrer por livre iniciativa dos municípios, de maneira voluntária, devendo a formação das instâncias de governança do circuito envolver a participação social, o compartilhamento de responsabilidades e a cooperação multissetorial. O modelo pressupõe a participação ativa da sociedade para definição das prioridades necessárias ao desenvolvimento do turismo, participação que ocorreria por meio de uma metodologia de indução, visando com que as comunidades se envolvessem de modo ativo e consciente.

Esse modelo se justifica, de acordo com o ex-superintendente, por duas razões: a) uma razão técnica, em função da extensão do estado e do objetivo de aumentar a permanência média do turista e melhorar a infraestrutura local, que gerariam então mais renda e trabalho para as regiões e, ainda, em função da possibilidade de articulação dos agentes das regiões turísticas do estado em uma rede de cooperação; e b) outra razão política, que visava a obter da política de turismo maior alcance sobre o território, e que, por isso, proporcionaria mais visibilidade ao então secretário de turismo.

\footnotetext{
${ }^{9} \mathrm{Na}$ maioria dos casos, desde meados do século passado, diversos órgãos estaduais de turismo já funcionavam por meio de nomenclaturas diversas.
} 
Verificou-se que seria impossível trabalhar com municípios isoladamente, [...] e a diretriz do Ministério [Esporte e Turismo] era trabalhar a municipalização. Mas, em Minas, se identificou antes que era inviável trabalhar com a municipalização, pela extensão. Já houve uma ideia de regionalizar. E também foi para o secretário, que era um secretário político, que era deputado, uma plataforma política importante para ele.

Considera-se que a regionalização e a descentralização são critérios que fundamentam a política de estado de turismo em Minas Gerais. Além dos fatores mencionados (técnicos e políticos), outros fatores contribuem para a adoção do modelo regionalista dos circuitos turísticos mineiros. Em âmbito internacional, havia a referência do modelo regionalista francês, o que não se pode desprezar já que a França era maior receptora de turistas internacionais do mundo. A política francesa, conforme Oliveira (2008), baseia-se igualmente em circuitos, definidos como um roteiro turístico temático ou com uma motivação turística específica. Um circuito aos moldes franceses deveria, então, constituir-se num produto turístico formatado e comercializável, capaz de reunir os principais atrativos de uma ou mais regiões, agregando valor ao circuito e aumentando seu trajeto.

Em âmbito nacional, uma experiência de moldes semelhantes estava sendo implementada: o Programa de Ação para o Desenvolvimento do Turismo - PRODETUR. O Programa foi criado em 1991 em razão dos resultados insatisfatórios alcançados pela atividade turística no Brasil, principalmente em função da falta de políticas adequadas (BOLSON; PIRES, BAHIA, 2005), e foi a primeira experiência no campo de desenvolvimento turístico regional a ser implementada no País, pois sua execução envolvia a identificação e o planejamento prévios de regiões turísticas.

Em sua primeira etapa, que durou dez anos (1994-2004), a área de abrangência do PRODETUR envolvia os nove estados do Nordeste e a área da Sudene de Minas Gerais. Nessa fase, em parceria com o Banco do Nordeste, apenas o Banco Interamericano de Desenvolvimento (BID) investiu mais de US\$ 700 milhões em 11 estados (BID, 2017). Segundo o Banco, os investimentos eram orientados por estratégias de desenvolvimento turístico elaboradas em cada estado.

Já na segunda fase, o território mineiro foi contemplado na totalidade e foram disponibilizados mais US\$ 600 milhões. O PRODETUR tinha, como objetivo central, o desenvolvimento turístico regional, estruturado e concebido pelos governos federal e estaduais para financiar a implantação de infraestrutura de suporte ao turismo (aeroportos, pavimentação de vias e rodovias), propiciando e incentivando investimentos da iniciativa privada para implantação de equipamentos turísticos (urbanização de faixas litorâneas, recuperação de sítios históricos) (BID, 2017).

Assim, supõe-se que o conhecimento, por parte dos formuladores, sobre as políticas regionalistas e descentralizadoras anteriores, e seus arranjos e mecanismos administrativos, como o 
PNMT, o PRODETUR e o modelo francês, sem mencionar outras possíveis, foi utilizado no desenho da política de turismo de Minas Gerais, uma vez que as informações sobre os efeitos dessas políticas já eram conhecidos, e poderiam orientar o design da política e justificar tomadas de decisões. Não se pretende, contudo, mensurar os graus dessa interferência, apenas mencionar que a política de turismo nascente não surge no vazio institucional, político ou ideológico, e que os critérios que fundamentam a política de turismo de Minas Gerais, a descentralização e a regionalização, já estavam presentes em políticas anteriores, tanto no Brasil, como no exterior.

Ainda se deve mencionar que a política de turismo mineira está circunscrita a um contexto neoliberal, de reforma do estado, em que se questionava o tamanho, o papel e a capacidade financeira do estado, e ideias, como descentralização e flexibilização administrativa, ganhavam espaço em todas as esferas do governo brasileiro, aos moldes de referências internacionais. No Brasil, o movimento teve inspiração nas reformas gerenciais implementadas, desde a década de 1980, em países, como GrãBretanha, Estados Unidos e Austrália, interessados em resolver a ineficiência estrutural da administração pública burocrática. A crise brasileira da década de 1980 foi vista como crise do estado, que teria se desviado de suas funções básicas, o que acarretou deterioração dos serviços públicos, e umas das alternativas centrais para a crise estatal era o fortalecimento da ação reguladora do estado, tendo em vista a abertura nacional à economia de mercado, em detrimento da função provedora do estado.

No País, esse movimento ganhou força nos anos 1990. A crise do nacional desenvolvimentismo e as críticas ao patrimonialismo e autoritarismo do estado brasileiro estimularam a emergência de um consenso político de caráter liberal. Nesse contexto, a administração pública gerencial, também conhecida como nova administração pública, emergiu como o modelo ideal para o gerenciamento do estado, pela adequação ao diagnóstico da crise do estado e pelo alinhamento em relação às recomendações do Consenso de Washington para os países latino-americanos.

Nesse sentido, a Constituição de 1988 e as reformas do estado empreendidas a partir da década de 1990 propõem uma transformação significativa na concepção da política pública brasileira, que trará impactos para a política de turismo do estado de Minas Gerais. A SETUR, criada em 1999, dá início à elaboração de uma política pública de turismo descentralizada, nos moldes do Programa Nacional de Municipalização do Turismo (PNMT), ao buscar, por meio da sensibilização e mobilização, formar unidades gestoras do turismo em nível municipal e regional. O estado e os municípios, por seu turno, assumem papeis assimetricamente interdependentes na construção da política. Ao estado de Minas Gerais coube o papel de formulador da política, responsabilizando-se pela criação do projeto dos circuitos turísticos, e aos municípios, a execução da política, por meio de 
AVALIAÇÃO POLÍTICA DA POLÍTICA DE

ESTADO DE TURISMO DE MINAS GERAIS
Mariana Pereira Chaves Pimentel Thiago Duarte Pimentel

associações sem fins lucrativos, formadas pela integração de municípios, gestores públicos, iniciativa privada e sociedade civil. O governo federal aparecia como grande incentivador, enquanto a iniciativa privada surgia como parceira e investidora, e a comunidade local ajudava na deliberação, execução e conscientização para o turismo na região (EMMENDOEFER et al., 2007).

Nesse sentido, a política de turismo mineira adequa-se ao modelo gerencialista ao delimitar as tarefas públicas e não públicas; ao privilegiar as parcerias entre os entes federativos e entidades públicas e privadas; ao estimular os roteiros integrados e os consórcios de cooperação intermunicipal; ao definir as atividades pertinentes ao estado e aos municípios; e ao estabelecer uma divisão entre as funções de formulação e execução. A política, nesse sentido, conforma-se a uma ambiguidade típica do novo modelo gerencialista de administração pública, que tem o processo de decisão e formulação das políticas centralizado no Poder Executivo e descentralizado na fase de execução. A execução descentralizada da política, que deve contar com a participação de gestores municipais, empresários locais e/ou a comunidade em geral, encontrou nas regiões, inicialmente, um terreno propício, já que, segundo o ex-superintendente, "todas as regiões se interessaram em formatar seus circuitos e formar suas instâncias de governança", no intuito de ganhar maior atenção e investimentos do estado.

A política de circuitos e a SETUR tiveram, como principal proponente, o próprio Executivo estadual, nesse caso o governador do estado e o secretário de estado de Turismo, de acordo com o ex-Superintendente de Políticas de Turismo. Segundo o entrevistado, "foi uma coisa que partiu do próprio estado. Pois, naquele momento, as universidades de turismo ainda estavam sendo criadas, e não tinham uma força acadêmica. [...] Nem mesmo os empresários". Para o governador Itamar Franco, a criação da Secretaria de Estado do Turismo compunha as medidas de reforma administrativa necessárias para conter os gastos do estado, ao suprimir a Empresa de Apoio ao Turismo no Estado, a TurMinas (FOLHA DE S. PAULO, 17 de junho de 1999).

Segundo o ex-superintendente, a substituição da TurMinas por uma Secretaria de Estado de Turismo implica mudanças institucionais que envolvem perdas e ganhos. A adoção de uma Secretaria perde em agilidade e efetividade, ao passo que ganha em visibilidade e recursos para a pasta.

O modelo de administração direta que é a Secretaria dá mais visibilidade, que é o fato de ter um secretário mais próximo ao governador com a possibilidade de captar recursos maiores, ter uma visibilidade política maior. Por outro lado, é um modelo mais engessado, com a legislação mais rígida. E a TurMinas tinha uma flexibilidade maior e uma visibilidade menor. Então, aumentou, sem dúvida, a visibilidade do turismo com a Secretaria, mas teve menos flexibilidade. 
AVALIAÇÃO POLÍTICA DA POLÍTICA DE

ESTADO DE TURISMO DE MINAS GERAIS
Mariana Pereira Chaves Pimentel Thiago Duarte Pimentel

O ex-superintendente nota, ainda, que a instituição de uma secretaria de estado está sujeita a sofrer de um trade-off entre maiores recursos ou maior efetividade, pois tende a obter maiores recursos quando assume um secretário político, porém propende a obter melhores resultados quando há um secretário técnico.

[...] o secretário mais político tem a vantagem de conseguir mais recurso, ele tem relacionamentos para trazer mais recursos e visibilidade para as questões da Secretaria. O secretário técnico a vantagem é que ele direciona as ações para aquelas que realmente são efetivas e dão resultados. Ele foca naquilo que vai dar retorno, enquanto o político tem outros interesses.

Em síntese, tem-se que i) os critérios que fundamentam a política de turismo em Minas Gerais são a descentralização e a regionalização; ii) adotadas pelo executivo estadual, em função dos valores e ideais gerencialistas, no contexto de reforma do estado, em âmbito nacional, contexto este marcado por crise econômica, em que crescia o sentimento de que o turismo seria uma alternativa de crescimento e desenvolvimento socioeconômico; iii) em um momento de remodelamento administrativo, em âmbito estadual, em razão da instituição da Secretaria de Estado de Turismo, que favoreceu um processo de formulação independente de linearidades e continuidades com políticas e arranjos precedentes; iv) mas que, ao mesmo tempo, sofreu influências de diversos canais, como do ideário de organizações internacionais e de modelos nacionais e estrangeiros.

\section{Considerações finais}

Neste trabalho, buscou-se investigar quais atores, contexto, ideias, valores e critérios estão na gênese da política de estado de turismo de Minas Gerais, adotada em fins da década de 1990. Quanto aos resultados encontrados, tem-se que o contexto econômico, político e administrativo para a formulação da política foi a reforma gerencialista do estado, que permitiu a revisão de papeis e atividades, até então atribuídas ao estado, e a rearticulação entre as esferas de governo e entre o governo e entidades privadas e da sociedade civil. O fato de o turismo chegar à década de 1990 considerado como uma importante alternativa de desenvolvimento econômico, em conformidade com diretrizes de organismos internacionais desde os anos de 1960, também não pode ser descartado, principalmente após uma década de crise. A partir desse período, o turismo entra na agenda do governo federal e de governos estaduais em todo o País. Não foram encontradas, na literatura, e mesmo em fonte primária, influências de grupos de interesse ou de outras fontes de pressão econômico-política sobre os tomadores de decisão. 
A principal força política definidora da política de estado de turismo em Minas Gerais, considera-se, foi o Executivo estadual, representado pelo secretário de turismo e pelo governador do estado. Vale ressaltar que o arranjo institucional estabelecido com a criação da Secretaria, de certo modo disruptivo em relação relações de poder, estruturas administrativas e burocráticas, rubricas financeiras e mecanismos de execução anteriores, permitiu a elaboração de uma política sem as prerrogativas de continuísmo e conformidade com políticas antecessoras. Por essa razão, acredita-se, os critérios que fundamentam a política mineira, descentralização e regionalização, são novidades na gestão pública do turismo no País. Uma política de turismo descentralizada, o PNMT, vinha sendo experimentada desde 1994, mas seus resultados ainda eram pouco conhecidos em 1999. A regionalização, igualmente, tinha o PRODETUR e o modelo da França, especialmente, como lições inspiradoras.

Portanto, e finalmente, pode-se considerar que a política de estado de turismo de Minas Gerais é resultado de uma janela de oportunidade política, que, conforme Kingdon (2011), abre-se quando convergem três fluxos de variáveis: a percepção pública dos problemas, o conhecimento de soluções políticas e técnicas adequadas aos valores dominantes e as condições de governação. A percepção do turismo, como uma questão pública, emerge na década de 1990, resultado de pressões internacionais desde a década de 1960; as primeiras soluções para o problema começam a ser experimentadas no País, segundo o ideário dominante no período, o gerencialismo, além dos modelos internacionais que servem de lições inspiradoras; e, ainda, a criação de uma nova Secretaria, que torna o ambiente institucional propício a inovações na agenda pública.

Confirma-se, então, a suposição de que as inovações propostas com a criação da SETUR e com a política de turismo, nos moldes adotados, produziram transformações estratégicas, administrativas e operacionais na gestão de turismo no estado que envolveram mudanças, desde o processo de tomada de decisões às formas de implementação e operação das ações no território mineiro. Ainda que tais ações sugiram ser fruto da atuação do executivo estadual, de forma ad hoc isto é, possivelmente influenciado preponderantemente pelo perfil dos ocupantes da secretaria à época (ainda que) - guiado pelos princípios da NPM, materializadas por meio de uma síntese assistemática em programas e projetos que priorizaram oportunisticamente temas e formas valorados no contexto da época.

\section{Referências}

ABRUCIO, F. Trajetória recente da gestão pública brasileira: um balanço crítico e a renovação da agenda de reformas. Revista de Administração Pública, Rio de Janeiro, vol. 41, n. ${ }^{\circ}$ especial, 
2007.

ALMEIDA, F. A. B.; CASTRO, J. F. de. Planejamento do turismo de base comunitária: perspectivas críticas. Caderno Virtual de Turismo. Rio de Janeiro, vol. 17, n. ${ }^{\circ}$ 3, p. 66-81, dez. 2017.

ARAUJO, L.; RODRIGUES, M. L. Modelos de análise das políticas públicas. Sociologia, Problemas e Práticas, n. ${ }^{\circ}$ 83, Lisboa, 2017.

ARRETCHE, M. Mitos da descentralização: mais democracia e eficiência nas políticas públicas. Revista Brasileira de Ciências Sociais, vol.11, n. ${ }^{\circ}$ 31, p. 44-66, 1996.

BID - Banco Interamericano de Desenvolvimento. Turismo em alta, 1 de novembro de 2011. Disponível em: http://www.iadb.org/pt/noticias/artigos/2011-11-01/prodetur-no-brasil,9505.html. Acesso em: 5 maio 2017.

BOLSON, J. Circuitos turísticos de Minas Gerais: Modelo de regionalização. Revista Turismo, ago. 2004. Disponível em: http://www. revistaturismo. com/artigos.

; PIRES, F.; TRINDADE, E. Histórico e análise das políticas públicas de turismo no Brasil 1930/2004: estudo de caso Minas Gerais. Revista de Estudos Turísticos, vol.. 5, 2005.

BORTOLOSSI; Simone C. F.; MANTOVANELLI JÚNIOR, Oklinger; SAMPAIO, Carlos A. C.; GUZATTI, Thaise C. O programa de regionalização do turismo em Santa Catarina: um estudo de caso sobre o Vale Europeu. In: PIMENTEL, Thiago D.; EMMENDOERFER, Magnus L.; TOMAZZONI, Edegar L. Gestão Pública do Turismo no Brasil: teorias, metodologias e aplicações. Caxias do Sul, RS; EDUCS, 2014 (capítulo 14, p.353-380).

BÖRZEL, T. Organizing Baylon on the diferents conceptions of policy networks. Public Administration, vol. 76, 1998.

BRESSER-PEREIRA, L. C. B. A reforma do estado dos anos 90: lógica e mecanismos de controle. Revista de Cultura e Política Lua Nova, São Paulo, n. ${ }^{\circ}$ 45, 1998.

Reflexões sobre a reforma gerencial brasileira de 1995. Revista do Serviço Público, vol. 50, . $^{\circ} 4,1999$.

BROOKS, S. Public Policy in Canada. Toronto: McClelland \& Stewart, 1993.

CAPANEGRA, C. El desarrollo turístico como estrategia política del Estado: de la política en turismo a la política turística Argentina 1900-1975. Aportes y Transferencias, vol. 14, n. ${ }^{\circ}$ 1, 2010.

CARVALHO, Fabíola C. C. de. Agenda governamental e trajetória institucional do turismo no Brasil. Anais Brasileiros de Estudos Turísticos - ABET, [S. 1.], p. 59-70, jul. 2015. ISSN 22382925. Disponível em: <http://ojs2.ufjf.emnuvens.com.br/abet/article/view/3054>. Acesso em: 12 fev. 2019.

; PIMENTEL, Thiago D. Fatores condicionantes do planejamento e da gestão em destinos turísticos: um quadro teórico de análise. In: PIMENTEL, Thiago D.; EMMENDOERFER, Magnus L.; TOMAZZONI, Edegar L. Gestão Pública do Turismo no Brasil: teorias, metodologias e aplicações. Caxias do Sul/RS: EDUCS, 2014 (capítulo 6, p.151-190). 
CAVALCANTI, Paula A. Sistematizando e comparando os enfoques de avaliação e de análise de politicas publicas: uma contribuição para a área educacional. Tese (doutorado) Universidade Estadual de Campinas, Faculdade de Educação, Campinas/SP, 2007. Disponível em: <http://www.repositorio.unicamp.br/handle/REPOSIP/252127>. Acesso em: 13 mar. 2018.

CONTE, Sibele; COLLETO, Cassia; TRAVERSO, Luciana D.; ELESBÃO, Ivo. Dissonâncias e afinidades do setor público e trade turístico: uma análise do município de Joaçaba/SC. In: PIMENTEL, Thiago D.; EMMENDOERFER, Magnus L.; TOMAZZONI, Edegar L. Gestão pública do turismo no Brasil: teorias, metodologias e aplicações. Caxias do Sul/RS; EDUCS, 2014. (capítulo 16, p.405-430).

CUNHA, P. O debate em torno das políticas públicas: o caso da política nacional de juventude no Brasil. Seminário Nacional de Ciência Política: Democracia em debate. Universidade Federal do Rio Grande do Sul — UFRGS. Porto Alegre, 2008.

DA MATA, Gilberto M. F., PIMENTEL, Thiago D.; EMMENDOERFER, Magnus L. Teoria do campo social e políticas públicas: o caso do Conselho Gestor de Turismo de Juiz de Fora, MG, Brasil. Revista Rosa dos Ventos Turismo e Hospitalidade, vol.10, n. ${ }^{\circ}$ 2, p. 332-354, 2018. DOI: http://dx.doi.org/10.18226/21789061.v10i2p332.

DE LA ROSA FLORES, Beatriz Adriana; CRUZ JIMÉNEZ, Graciela; PORRAS, Francisco. Redes de política, élites y gobernanza: marco teórico para el estudio de un caso turístico. PASOS. REVISTA DE TURISMO Y PATRIMONIO CULTURAL [en linea] 14 jun./set. 2016. Disponível em:<http://www.redalyc.org/articulo.oa?id=88145925003> ISSN 1695-7121. Acesso em: 12 fev. 2019.

DOLOWITZ, D. MARSH, D. Learning from abroad: the role of policy transfer in contemporary policy-making. An International Journal of Policy and Administration, vol. 13, n. ${ }^{\circ}$ 1, p. 5 24, jan. 2000.

. The future of policy transfer research. Political Studies Review, 2012.

DUARTE, Donária C.; BORDA, Gilson Z.; MOURA, Danielle G.; SPEZIA, Domingos S. Turismo acessível no Brasil: um estudo exploratório sobre as políticas públicas e o processo de inclusão das pessoas com deficiência. Revista Brasileira de Pesquisa em Turismo, vol. 9, n. ${ }^{\circ} 3$, set./dez.; p. 537-553, 2015.

DUNLOP, C.; RADAELLI, C. Systematizing policy learning: from monoliths two dimensions. Political Studies, dez. 2012.

DYE, Thomas. Understanding public policy. New York: Longman, 2009.

EASTON, D. An approach to the analysis of political systems. World Politics, vol. 9, n. ${ }^{\circ}$. 3, p. 383400, abr. 1957.

EMBRATUR - Instituto Brasileiro de Turismo. Diretrizes do programa nacional de municipalização do turismo. EMBRATUR, Brasília, 1999. 
EMMENDOERFER, L. A política pública de regionalização do turismo em Minas Gerais: os circuitos turísticos. Turismo em Análise, vol.19, n. ${ }^{\circ}$ 2, 2008.

; SILVA, Luis F. T. B.; EMMENDOERFER, Magnus, L.; FONSECA, Poty C. A formação dos circuitos turísticos mineiros: uma política pública descentralizada $\mathrm{e}$ democratizante?.Observatório de Inovação do Turismo, vol. 2, n. ${ }^{\circ}$, 2007.

EMMENDOERFER, Magnus L.; SOARES, Érica B. S.; ARAÚJO, Joaquim F. E. F. de; MENDES, Júlio da C., CUNHA, Nina Rosa da Silveira. Destinos indutores e desenvolvimento turístico regional: um problema de intergovernabilidade? PASOS - Revista de Turismo y Patrimonio Cultural [en linea] 14, jun./set. 2016. Disponível em: <http://www.redalyc.org/articulo.oa?id=88145925012> ISSN 1695-7121. Acesso em: 12 fev. 2019.

; SOUZA, F.; LORETO. A política de circuitos turísticos de Minas Gerais: uma avaliação baseada na percepção de agentes estratégicos. PASOS - Revista de Turismo y Patrimonio Cultural, vol.10, . $^{\circ} 3,2012$.

ENDRES, Ana V. As políticas de turismo no Brasil e os novos arranjos institucionais na Paraíba: o papel das organizações locais. In: PIMENTEL, Thiago D.; EMMENDOERFER, Magnus L.; TOMAZZONI, Edegar L. Gestão pública do turismo no Brasil: teorias, metodologias e aplicações. Caxias do Sul/RS: EDUCS, 2014 (capítulo 4, p. 91-124).

; PAKMAN, E. T. A governança das políticas de turismo: o papel dos espaços de participação na perspectiva da análise de redes e da teoria institucional. Revista Brasileira de Pesquisa em Turismo, São Paulo, vol. 13, n. ${ }^{0}$ 1, p. 1-18, jan./abr., 2019. http://dx.doi.org/10.7784/rbtur.v13i1.1431.

ESPING-ANDERSEN, Gosta. As três economias políticas do Welfare State. Lua Nova, n. ${ }^{\circ} 24$, p. 85116, set. 1991.

FARAH, M. Análise de políticas públicas no Brasil: de uma prática não nomeada à institucionalização do "campo de públicas". Revista de Administração Pública, vol. 50, n. ${ }^{\circ}$ 6, 2016.

- Parcerias, novos arranjos institucionais e políticas públicas no nível local de governo. Revista de Administração Pública, vol. 35, n. ${ }^{\circ}$ 1, p. 119-144, 2001.

FARIA, C. A. P. de. A política da avaliação de políticas públicas. Revista Brasileira de Ciências Sociais, vol. 20, n. ${ }^{\circ} 59,2005$.

- Ideias, conhecimento e políticas públicas: um inventário sucinto das principais correntes analíticas recentes. Revista Brasileira de Ciências Sociais, vol. 18, n. ${ }^{\circ}$ 51, 2003.

FEGER, José E.; ETGES, Virgínia E. Regionalização para o Planejamento do Desenvolvimento Turístico: uma discussão sobre critérios para a determinação de áreas com vistas a aplicar a política pública para o setor. In: PIMENTEL, Thiago D.; EMMENDOERFER, Magnus L.; TOMAZZONI, Edegar L. Gestão Pública do Turismo no Brasil: teorias, metodologias e aplicações. Caxias do Sul, RS; EDUCS, 2014. (Capítulo 9, pp.231-256). 
FERRONI, Marco; MATEO-BERNANZA DIAZ, Maria Mercedes; PAYNE, J. Mark. La cohesión social en América Latina y el Caribe: análisis, acción Análisis, acción y coordinación. In. BID - Banco Interamericano de Desenvolvimento, 2006.

FIGUEIREDO, M.; FIGUEIREDO, A. Avaliação política e avaliação de políticas: um quadro de referência teórica. Anal. e Conj., Belo Horizonte, vol. 1, n. ${ }^{\circ}$ 3, p. 107-127, set./dez., 1986.

FOLHA DE SÃO PAULO. Itamar anuncia medidas para diminuir gastos do estado, 17 de junho de 1999. Disponível em: http://www1.folha.uol.com.br/fsp/brasil/fc17069917.htm. Acesso em: 5 maio 2017.

FRAGA, Brendow de O.; LAZARONI, Alice R. B.; EMMENDOERFER, Magnus L.; MATA, Gilberto M. F. da. Aprendizagem na gestão pública municipal para o desenvolvimento turístico. Anais Brasileiros de Estudos Turísticos - ABET, vol.6, n. ${ }^{0} 3$, set./dez. (ed. temática: Turismo e Organização Socioespacial), 2016.

FRATUCCI, Aguinaldo. A Dimensão espacial das políticas públicas de turismo no Brasil. In: PIMENTEL, Thiago D.; EMMENDOERFER, Magnus L.; TOMAZZONI, Edegar L. Gestão pública do turismo no Brasil: teorias, metodologias e aplicações. Caxias do Sul/RS: EDUCS, 2014 (capítulo 2, p. 39-64).

FREY, K. Análise de políticas públicas: algumas reflexões conceituais e suas implicações para a situação brasileira. Cadernos de Pesquisa, Florianópolis, n. ${ }^{0} 18,1999$.

FUCHS, Andréa M. S. L.; OLIVEIRA, Frederico F. de. ICMS turístico e novas possibilidades de desenvolvimento regional para o estado de Minas Gerais. ABET - Anais Brasileiros de Estudos Turísticos, Juiz de Fora, vol.2, n. ${ }^{\circ}$ 2, p. 54-64 jul./dez. 2012.

GERHARDT, T.; SILVEIRA, D. (Orgs.). Métodos de pesquisa. Porto Alegre, Editora da UFRGS, 2009.

GOMES, B.; SILVA, V.; SANTOS, A. Políticas públicas de turismo: uma análise dos circuitos turísticos de Minas Gerais sob a concepção de cluster. Revista Turismo em Análise, vol. 19, n. ${ }^{\circ}$ 2, p. 201-220, 2008. https://doi.org/10.11606/issn.1984-4867.v19i2p201-220.

GOMES, Bruno M. A.; GANDARA, Jose M. G. Metodologia do marco lógico aplicada à gestão pública do turismo. In: PIMENTEL, Thiago D.; EMMENDOERFER, Magnus L.; TOMAZZONI, Edegar L. Gestão Pública do Turismo no Brasil: teorias, metodologias e aplicações. Caxias do Sul/RS: EDUCS, 2014 (capítulo 8, p..211-230).

GONNET, C. ¿Cómo viajan las ideas? El rol de las comunidades epistémicas en el diseño de políticas sociales en América Latina. Revista del CLAD Reforma y Democracia, n. ${ }^{\circ}$ 68, p. 75-112, jun. 2017.

HAAS, P. Introduction: Epistemic communities and international policy coordination. In: International Organization, vol. 46, n. ${ }^{\circ} 1$ (Knowledge, Power, and International Policy Coordination), p. 1-35,1992,

HALL, C. M.; JENKINS, J. Tourism and public policy: A companion to tourism, 2004. 
HECLO, H. Issue networks and the executive establishment. In: KING, A. The new American political system. Washington: American Institute for Public Policy Research, 1978.

KINGDON, John W. Agendas, alternatives and public policies. Boston: Longman, 2011.

KNUPP, Marcos E. C. G. Análise de políticas públicas de turismo: uma abordagem metodológica baseada em redes sociais. In: PIMENTEL, Thiago D.; EMMENDOERFER, Magnus L.; TOMAZZONI, Edegar L. Gestão Pública do Turismo no Brasil: teorias, metodologias e aplicações. Caxias do Sul, RS; EDUCS, 2014 (capítulo 11, p. 285-316).

; NAVES, Flávia. Redes do turismo: uma análise da política de turismo do estado de Minas Gerais/Brasil. Turismo em Análise, vol. 23, n. ${ }^{\circ}$ 3, 2012.

HOWLETT, M; RAMESH, M. Studing public policy: policy cycles and policy subsystems. Ontario: Oxford/ University Press, 1995.

KUPER, D.; RAMÍREZ, L.; TRONCOSO, C. Política turística y planificación: ¿ de las estrategias centralizadas a las estrategias participativas? Scripta Nova: revista electrónica de geografía y ciencias sociales, (14), 41, 2010.

LEITE, Ramon S.; LOPES, Humberto E. G.; MOORI, Roberto G. Relacionamentos colaborativos e desempenho: uma análise sob a perspectiva dos clientes. Revista Encontros Científicos Tourism \& Management Studies, vol 11, n. ${ }^{\circ}$ 2, p. 112-119, 2015.

LOWI, T. American business, public policy, case-studies, and political theory. World Politics, vol. $16,{ }^{\circ} 4,1964$.

MALHOTRA, N. K. Pesquisa de marketing: uma orientação aplicada. São Paulo: Artmed, 2004.

MARQUES, E. Redes sociais e poder no estado brasileiro: aprendizados a partir das políticas urbanas. Revista Brasileira de Ciências Sociais, vol. 21n. ${ }^{\circ}$ 60, p. 15-41, 2006.

MATHEUS, Fabricio S.; RAIMUNDO, Sidnei. Os resultados das políticas públicas de ecoturismo em unidades de conservação no Brasil e no Canadá. Revista Brasileira de Pesquisa em Turismo; vol. 11, n. ${ }^{\circ}$ 3, p. 455-479, set./dez. 2017.

MELO, M. A. As sete vidas da agenda pública brasileira. In: RICO, E. M. (Org.). Avaliação de políticas sociais: uma questão em debate. São Paulo: Cortez/IEE, 1996.

MELO, Rodrigo de S.; MONTEIRO, Maria do Socorro L. Turismo de baixo carbono como ferramenta para a gestão sustentável de destinos turísticos. In: PIMENTEL, Thiago D.; EMMENDOERFER, Magnus L.; TOMAZZONI, Edegar L. Gestão pública do turismo no Brasil: teorias, metodologias e aplicações. Caxias do Sul/RS: EDUCS, 2014 (capítulo 13, p.333-352).

MILANI, C. R. S. O princípio da participação social na gestão de políticas públicas locais: uma análise de experiências latino-americanas e europeias. Revista de Administração Pública, vol. 42, n. ${ }^{\circ} 3$, p. 551-579, 2008. 
NOBREGA, Wilker R. de M.; FIGUEIREDO, Silvio L. Turismo e gestão pública: uma avaliação das instancias de governança no oeste do estado do Pará. In: PIMENTEL, Thiago D.; EMMENDOERFER, Magnus L.; TOMAZZONI, Edegar L. Gestão pública do turismo no Brasil: teorias, metodologias e aplicações. Caxias do Sul/RS: EDUCS, 2014 (capítulo 17, p.431-462).

OCDE - Organização para Cooperação e Desenvolvimento Econômico (2012). Organização para cooperação e desenvolvimento econômico. Tourism Trends and Policies, OECD Publishing.

OLIVEIRA, F. As políticas de turismo no Brasil nos anos noventa. Revista Turismo em Análise, vol. 19, n. ${ }^{\circ} 2$, p. 177-200, 1 ago. 2008.

OLIVEIRA, Rafael A. de. Descentralização: um paralelo entre os circuitos turísticos de Minas Gerais e o modelo francês de regionalização do turismo. In: PIMENTEL, Thiago D.; EMMENDOERFER, Magnus L.; TOMAZZONI, Edegar L. Gestão pública do turismo no Brasil: teorias, metodologias e aplicações. Caxias do Sul/RS: EDUCS, 2014 (capítulo 5, p.125-150).

OLIVEIRA, Saulo B. de; LEITÃO, Márcia C. da S.; FILHO, Joaquim R. F. (2007). A governança em turismo regional: realidade: estudo de caso sobre o destino Estrada Real. In: XXXI Encontro da ANPAD. Rio de Janeiro, 2007.

ONU - Organização Das Nações Unidas. Recomendaciones sobre turismo y viajes internacionales, Conferencia de Roma, 1963.

PAIVA, M. G. M. Sociologia do turismo. Campinas/SP: Papirus, 1995.

PAIVA, P. Desafios à gestão das políticas públicas: velhos e novos temas. In: Primeiro Seminário Internacional de Gestão de Políticas Públicas. Anais... Belo Horizonte: DCP/UFMG, 2010.

PAUlA, Ana P. P. de. Por uma nova gestão pública: limites e potencialidades da experiência contemporânea. Rio de Janeiro: FGV, 2005.

PAULA, Angela T. de; MOESCH, Marutschka M. Pela transversalidade da questão social nas políticas públicas setoriais: um ensaio sobre as políticas públicas de turismo. Caderno Virtual de Turismo; vol. 13, n. ${ }^{\circ}$ 2, 2013.

PAULA, M. M. Institucionalização, estratégia de desenvolvimento e padrão de espacialização: eixos estruturantes para uma retrospectiva do planejamento governamental do turismo no Brasil. Caderno Virtual de Turismo. Rio de Janeiro, vol. 13, n. ${ }^{\circ}$ 2, p. 253-272, 2013.

PIMENTEL, Mariana P. C. Políticas públicas de educação em turismo na América Latina: um estudo comparado de Argentina, Brasil e México. Tese (doutorado). Universidade Federal de Juiz de Fora, 2016.

. Uma discussão teórica-metodológica para a análise de políticas de turismo no Brasil. In: PIMENTEL, Thiago D.; EMMENDOERFER, Magnus L.; TOMAZZONI, Edegar L. Gestão pública do turismo no Brasil: teorias, metodologias e aplicações. Caxias do Sul/RS: EDUCS, 2014 (capítulo 12, p.317-332). 
PIMENTEL, Mariana P. C.; PEREIRA, José R.; PIMENTEL, Thiago D.; CARRIERI, Alexandre de Pádua. As cinco vidas da agenda pública brasileira de turismo. Revista Acadêmica Observatório de Inovação do Turismo, vol. 6, n. ${ }^{\circ}$ 4, 2011.

PIMENTEL, Mariana P. C.; PEREIRA, Jose R.; Pimentel, Thiago D.; CARRIERI, Alexandre de P. As cinco vidas da agenda pública brasileira de turismo. Revista Acadêmica Observatório de Inovação do Turismo, [S. 1.], jan. 2012. ISSN 1980-6965. Disponível em: <http://publicacoes.unigranrio.edu.br/index.php/raoit/article/view/3500/1627>. Acesso em: 12 fev. 2019.

PIMENTEL, Thiago D., PIMENTEL, Mariana P. C. The public agenda of tourism in Brazil. Journal of Multidisciplinary Academic Tourism/JOMAT, vol. 3, n. ${ }^{\circ}$ 2, p. 23-31, dez. 2018. DOI: http://dx.doi.org/10.31822/jomat.492460.

PIMENTEL, Thiago D.; CARVALHO, Fabíola C. C. Mapeando os modelos de planejamento turístico: em busca de refinamento teórico com vistas à intervenção qualificada. In: X Seminário da Associação Nacional de Pesquisa e Pós-Graduação em Turismo/ANPTUR, 2013, Caxias do Sul (RS). Anais.... Caxias do Sul/RS: EDUCS, 2013, vol. 1. p. 1-15.

PIMENTEL, Thiago D.; PIMENTEL, Mariana P. C.; VIDAL, Josep P. Políticas públicas de turismo numa perspectiva normativa comparada: os casos de Brasil e Espanha. Pasos - Revista de Turismo e Patrimônio Cultural, vol. 15, n. ${ }^{\circ}$ 2, p. 293-310, 2017.

RAMOS, Silvana P. Apontamentos sobre a insustentabilidade de um programa político: o caso do Programa Monumenta em Penedo/AL. RITUR - Revista Iberoamericana de Turismo; vol. 5 (Número Especial "Turismo e Políticas Urbanas"), p. 148-168, 2015.

RUA, M. G. Análise de políticas públicas: conceitos básicos. Programa de apoio à gerência social no Brasil. Brasília: BID, 1997.

SAGI, Luciana C. Capacidade institucional para a gestão do turismo: definição de indicadores e análise com base no estudo de caso de Santa Catarina. Revista Hospitalidade, vol. 6, n. ${ }^{\circ} 1$, p. 51-76, jun. 2009.

SANTOS, B. S. (Org.).. Democratizar a democracia. RIo de Janeiro::Civilização Brasileira, 2002.

SCHENKEL, Érica. La inserción del turismo social a la agenda pública en Argentina. Papers de Turisme; n. ${ }^{\circ}$ 56, p.1-19, 2014.

SETTE, I.; VALLE, M.; COUTINHO, M. O programa de regionalização do turismo de Minas Gerais: uma abordagem da política pública estadual de turismo. Revista Turismo em Análise, vol. 25, n. $^{\circ} 3,2014$.

SETUR - Secretaria de Estado de Turismo de Minas Gerais. Institucional. Objetivo operacional e competências legais. Disponível em: http://www.turismo.mg.gov.br/institucional/politicainstitucional-de-turismo.

SILVEIRA, Carlos E.; MEDAGLIA, Juliana; PAIXÃO, Dario L. D. Política pública de turismo no Brasil: evolução estrutural, alteração de lógica partidária e tendências recentes de apoio ao turismo massificado. In: PIMENTEL, Thiago D.; EMMENDOERFER, Magnus L.; 
TOMAZZONI, Edegar L. Gestão pública do turismo no Brasil: teorias, metodologias e aplicações. Caxias do Sul/RS: EDUCS, 2014 (capítulo 3, p.65-90).

SOLÀ, Eduardo F.; MORALEDA, Laura F. M.; MAZÓN, Ana I. Elaborando un plan de política turística: consideraciones metodológicas. Papers de Turisme, n. ${ }^{\circ}$ 51; p. 40-65, 2012.

SOUZA, Celina. Políticas públicas: uma revisão de literatura. Revista Sociologias, vol. 8, n. ${ }^{\circ} 16$, 2006.

STONE, D. Global public policy, transnational policy communities, and their networks. Policy Studies Journal, vol. 36, p. 19-38, 2008.

TRENTIN, Fábia; FRATUCCI, Aguinaldo C. Política nacional de turismo no Brasil: da municipalização à regionalização. Revista Encontros Científicos - Tourism \& Management Studies; Proceedings TMS Algarve 2011: Full Papers, p. 839-848, 2011.

VELASCO GONZÁLEZ, María. Entre el poder y la racionalidad gobierno del turismo, política turística, planificación turística y gestión pública del turismo. PASOS Revista de Turismo y Patrimonio Cultural, vol. 14, n. ${ }^{\circ}$ 3, Special Issue, 2016.

. La política turística. Una arena de acción autónoma. Cuadernos de Turismo, n. ${ }^{\circ}$ 27, p. 953969, jan./jun. 2011.

WANDERLEY-FILHA, Iracy; AZEVEDO, Francisco F. de; NÓBREGA, Wilker R. de M.; ALBUQUERQUE, Jaci C. de. Planejamento e políticas públicas do turismo: uma discussão teórica no contexto das unidades de conservação do Brasil. Revista Brasileira de Ecoturismo, vol. 6, p. 27-44, 2013. Disponível em: <http://www.sbecotur.org.br/rbecotur/seer/index.php/ecoturismo/article/view/774/576>. Acesso em: 25 jan. 2019. 